\title{
FORMAÇÃO CONTINUADA: POSSIBILIDADES PARA A CONSTRUÇÃO DE UMA IDENTIDADE DENTRO DA PERSPECTIVA DA EDUCAÇÃO INTEGRAL
}

\author{
Gislene Francisconi de Costa ${ }^{1}$ \\ Gislene Camargo²
}

\begin{abstract}
RESUMO: A pesquisa realizada sob o título Formação Continuada: Possibilidades para a construção de uma identidade dentro da perspectiva da Educação Integral teve por objetivo geral Analisar a percepção dos professores para a construção de uma nova identidade pedagógica do Bairro da Juventude x EMEIEF. Pe. Paulo Petruzzellis dentro da perspectiva da Educação Integral. O referencial teórico foi fundamentado nas ideias e experiências de Titton (2012); Tardif (2014), Brandão (2012) entre outros. A presente pesquisa possui características descritivas, com abordagem qualitativa. Como instrumento de coletas de dados, foi utilizado o questionário estruturado. Constatamos que os professores participantes demonstraram clareza referente aos conceitos de tempo integral e educação integral, se mostraram comprometidos em tentar fazer educação integral, ou seja, entender que o currículo escolar é um espaço de disputa, onde os conteúdos são relevantes, mas as vivências trazidas pelas crianças e adolescentes também o são. Esta pesquisa demonstrou que os professores estão envolvidos na construção de uma educação mais humanizada e acreditam ser possível construir uma nova identidade pedagógica no Bairro da Juventude, envolvendo o ensino formal constituído pela escola EMEIEF. Pe. Paulo Petruzzellis, dentro da perspectiva da Educação Integral.
\end{abstract}

Palavras-chave: Educação em tempo integral. Formação continuada. Educação Integral

\section{CONTINUED TRAINING: POSSIBILITIES FOR THE CONSTRUCTION OF AN IDENTITY WITHIN THE PERSPECTIVE OF INTEGRAL EDUCATION}

SUMMARY: The research carried out under the title Continuing Education: Possibilities for the construction of an identity within the perspective of Integral Education had as general objective To analyze the perception of the teachers for the construction of a new pedagogical identity of the Bairro da Juventude $x$ EMEIEF. Paulo Petruzzellis from the perspective of Integral Education. The theoretical framework was based on the ideas and experiences of Titton (2012); Tardif (2014), Brandão (2012) and others. The present research has descriptive characteristics, with a qualitative approach. Structured questionnaire was used as data collection technique. We found that the questionnaires showed that teachers believe it is

\footnotetext{
${ }^{1}$ Graduada em Pedagogia. Mestranda do Programa de Pós-Graduação da Universidade do Extremo Sul Catarinense - PPGE/UNESC. Email: gifrancisconi@gmail.com
}

2 Graduada em Pedagogia pela Universidade do Extremo Sul Catarinense (1990) e Mestrado em Educação pela Universidade do Extremo Sul Catarinense. Email: gislene@unesc.net 
possible to construct a new pedagogical identity in the Youth District, involving the formal education constituted by the EMEIEF school. Fr. Paulo Petruzzellis, within the perspective of Integral Education.

Key words: Full-time education. Continuing education. Integral Education

\section{INTRODUÇÃO}

O presente artigo tem a intenção de discutir e investigar, se os professores da Instituição Bairro da Juventude e EMEIEF. Pe. Paulo Petruzzellis entendem o processo de Formação Continuada como instrumento para a construção de uma nova identidade dentro da perspectiva da Ed. Integral. Entende-se desse modo, que a identidade da instituição passa necessariamente pelo entendimento dos professores sobre os pressupostos da instituição. Dentro deste questionamento apontou-se o seguinte problema investigativo: É possível construir uma identidade dentro da perspectiva da educação integral, envolvendo Bairro da Juventude e EMEIEF Pe. Paulo Petruzzellis, por meio de formação continuada? Diante desta temática as autoras levantaram alguns objetivos. Tendo por objetivo geral: Analisar a percepção dos professores sobre a construção de uma nova identidade pedagógica do Bairro da Juventude x EMEIEF. Pe. Paulo Petruzzellis dentro da perspectiva da Educação Integral. E por objetivos específicos: Apresentar a Instituição Bairro da Juventude e EMEIEF. Pe. Paulo Petruzzellis, analisar como os professores avaliam as atividades em tempo integral e se já é realizada educação integral; identificar o conhecimento dos professores em relação à educação integral e analisar as necessidades/dificuldades expressas pelos professores investigados para atendimento na perspectiva da educação integral; verificar junto aos investigados quais são as contribuições da Formação Continuada para o atendimento na perspectiva de educação integral.

Esta razão justifica a necessidade da realização da presente pesquisa que se constituiu como sendo básica quanto a sua natureza. "Entende-se por pesquisa básica o processo de geração de conhecimentos novos para o avanço da ciência, sem preocupação com aplicação prática imediata" (SIENA, 2007, p. 59). A abordagem do problema de pesquisa foi qualitativa, pois para Oliveira (2007, p.37) "a pesquisa 
qualitativa tem um processo de reflexão e análise da realidade através da utilização de métodos e técnicas para compreensão detalhada do objeto de estudo em seu contexto histórico e /ou segundo sua estruturação".

Levando-se em consideração os objetivos propostos, o estudo caracterizou-se por ser, também, descritivo e exploratório, pois foi a primeira vez que foi abordada esta temática no curso de pós-graduação da Unesc de forma vinculada a instituição do Bairro da Juventude e o ensino integral. Exploratório porque teve como finalidade viabilizar maiores informações sobre o assunto investigado, facilitando a delimitação de uma temática de estudos ou, ainda, descobrir um novo enfoque para o estudo que se pretende realizar (ACAFE, 2007).

A pesquisa foi realizada com 8 (oito) professores que atendem crianças e adolescentes do Ensino Fundamental: 1 (um) da Educação Infantil, 1 (um) dos Laboratórios Educativos, 2 (dois) do Ensino Fundamental I (1ํaำ ano) ,2 (dois) do Ensino Fundamental II (6을 a $9^{\circ}$ ano) , 2 (dois) das Oficinas Culturais e Esportivas (4 ano ao $9^{\circ}$ ano). Dentre os professores participantes da pesquisa, 4 (quatro) professores são contratados pela instituição Bairro da Juventude e 4 (quatro) pelo sistema municipal de ensino na modalidade de ACT (Admitido em caráter temporário). Enquanto instrumento de coleta de dados, optou-se por questionário estruturado, com um roteiro previamente elaborado contendo 6 (seis) questões, porém flexíveis, pois se pode acrescentar novos questionamentos quando necessário para 0 aprimoramento dos dados coletados. De acordo com autorização dos pesquisados, os questionários foram analisados para a sistematização e tabulação dos dados a fim de possibilitar a realização da análise frente ao referencial teórico.

\section{ADENTRANDO A INSTITUIÇÃO}

Bairro da Juventude vem contando e escrevendo a sua história por mais de seis décadas, tudo iniciou em 1949 quando foi fundada a SCAN (Sociedade Criciumense de Apoio aos Necessitados), nesta época se constituiu como instituição com a finalidade assistencial, onde visava "tirar" os meninos das ruas, com funcionamento em formato de internato (BAIRRO DA JUVENTUDE, 2016). Mas ao 
longo dos anos essa realidade foi mudando, entendendo-se que a educação é uma ferramenta de mudança social, e não atender ao apelo social assistencialista. Em 1994, a instituição já consolidada como o Bairro da Juventude, iniciou os atendimentos com uma proposta de ensino regular nascendo assim a escola Padre Paulo Petruzzellis, atendendo alunos da educação infantil até anos iniciais. Em 2004, firmouse o convênio com o município de Criciúma/SC, por meio do decreto 115/2004, onde possibilitou o funcionamento da Escola Municipal de Ensino Fundamental Padre Paulo Petruzzellis.

\begin{abstract}
Art. $1^{\circ}$ é homologado, nos termos em que foi celebrado, o Termo de Convênio entre o Município de Criciúma e o Bairro da Juventude dos Padres Rogacionistas, registrado na Secretaria Municipal de Administração Departamento de Apoio Administrativo, sob o $n^{\circ} 750$, Livro 02, Fls. 06-v em 25.10.2004.Paragrafo único. O presente Convênio tem por objetivo possibilitar o funcionamento da Escola Municipal de Ensino Fundamental Padre Pedro Petruzzellis, criada pelo Decreto Municipal no 557/AS/94, com identificação alterada pela Lei $n^{\circ} 4.547$, de 23.10.2003, e atender as necessidades das crianças matriculadas regularmente naquela Unidade Educacional. Art. $2^{\circ}$ Este decreto legislativo entra em vigor na data de sua publicação (CRICIÚMA,2004).
\end{abstract}

No início eram atendidas crianças da Educação Infantil até o $5^{\circ}$ ano do Ensino Fundamental. Em 2005, a escola passou a ter educação em tempo integral, considerando o ensino regular e atividades de Laboratórios Educativos, Oficinas Culturais e Esportivas em turnos opostos. Vale ressaltar que os Laboratórios Educativos desenvolvem atividades para crianças de primeiro a terceiro ano do ensino fundamental, já as oficinas culturais e esportivas são oferecidas atividades onde as crianças e adolescentes do quarto ao nono ano do ensino fundamental escolhem o que gostariam de fazer, cada criança e adolescente constrói o seu horário. Já em 2008, aconteceu a ampliação do atendimento até os anos finais do Ensino Fundamental. Atualmente, 2016, o Bairro da Juventude atende mais de mil e quinhentas crianças e adolescentes, oportunizando transporte, alimentação, escola, laboratórios educativos, oficinas culturais e esportivas e ensino profissionalizante para alunos da instituição e também, de diversas escolas estaduais. A partir deste quadro foi possível reconhecer o movimento institucional de fomento e valorização da educação em tempo integral. 
O interesse por este estudo surgiu em meados de 2015 com a implantação de uma nova equipe pedagógica. A coordenação Geral do CEF (Centro de Ensino Fundamental) objetivou formar uma equipe que tivesse como foco as ações pedagógicas para aperfeiçoar o processo de ensino e aprendizagem. Nesse intento, percebeu-se a preocupação de que todas as crianças que frequentam o Bairro da Juventude / EMEIEF Pe. Paulo Petruzzellis recebessem uma educação de qualidade, além dos conteúdos escolares.

No início de 2016 a coordenação geral do CEF solicitou para equipe pedagógica um planejamento de capacitações para os professores, prática realizada há alguns anos, com encontro a cada dois meses para discutir assuntos relevantes às atividades desenvolvidas. Retomando o histórico das formações, percebeu-se que cada setor discutia com os seus integrantes os assuntos pertinentes ao grupo, porém, a nova equipe pedagógica pensou que dever-se-ia iniciar um programa de Formação Continuada que envolvesse os professores em um novo fazer pedagógico.

Percebeu-se que o primeiro projeto construído pela equipe foi uma "reprodução" das capacitações, pois sem se dar conta era proposta uma formação setorizada, cada nível de ensino e atividades de contra turnos eram divididos em grupos condizentes as atividades trabalhadas para dar encaminhamentos a assuntos específicos ao seu trabalho. Após algumas reflexões chegou-se à conclusão que é necessário fazer uma educação diferente, uma educação integradora, mais humanizada e que prepare a criança e adolescente para a vida.

\section{EDUCAÇÃO EM TEMPO INTEGRAL}

No país a educação em tempo integral, já trilha um longo caminho, as primeiras experiências aconteceram no Brasil colônia com os colégios jesuíticos, segundo Giolo (2012, p. 94) "Os colégios onde estudavam a elite imperial eram de tempo integral e, na maioria das vezes internos". Se a história da educação brasileira for analisada percebe-se que ainda hoje muitos filhos da elite recebem educação em tempo integral, os colégios particulares ofertam o contra turno com formação complementar, alguns exemplos como aulas de tênis, ballet, informática, inglês, entre 
outras, enfim, essas crianças acabam tendo mais acesso à outras línguas, arte, música, que os filhos das classes menos favorecidas.

O PNE (Plano Nacional de Educação) traz expresso em sua meta 06 a garantia de atendimento em tempo integral em pelo menos $50 \%$ das escolas públicas, uma das estratégias foi a implantação do programa Mais Educação, que considera educação em tempo integral o atendimento com duração igual ou superior a sete horas diárias, durante todo o período letivo.

\begin{abstract}
"Desenvolvimento de atividades de acompanhamento pedagógico, experimentação e investigação científica, cultura e artes, esporte e lazer, cultura digital, educação econômica, comunicação e uso de mídias, meio ambiente, direitos humanos, práticas de prevenção aos agravos à saúde, promoção da saúde e da alimentação saudável, entre outras atividades" (art. 1ㅇ, § 2º) (BRASIL, 2010).
\end{abstract}

O Programa lança a proposta e exige das escolas e dos profissionais envolvidos maior comprometimento com a educação, pois é necessário criar um projeto pedagógico que dê conta do currículo formal e das demais atividades, neste sentido, as atividades podem ir além dos espaços escolares.

"[...] desenvolvidas dentro do espaço escolar, de acordo com a disponibilidade da escola, ou fora dele, sob orientação pedagógica da escola, mediante o uso dos equipamentos públicos e o estabelecimento de parcerias com órgãos ou instituições locais" (art. 1ํㅛ § 3ํ) (BRASIL, 2010).

Nesta perspectiva, a educação em tempo integral é uma "preparação" para uma educação mais humanizada, em 2007 o Ministério da Educação lançou o programa Mais Educação, com o intuito de orientar a construção da agenda de educação integral nas redes estaduais e municipais de ensino ampliando a jornada escolar nas escolas públicas, para no mínimo 7 horas diárias, nesta perspectiva fezse necessário reinventar a escola , fazer diferente, "derrubar os muros", ampliar os espaços educativos, considerando que o meio e o outro podem contribuir para que a aprendizagem ocorra de forma espontânea e prazerosa. Freire (1993) lembra que é necessário superar a pedagogia das respostas, o professor/educador tem que se desvincular da figura de detentor do saber, provocando e estimulando a criança a 
questionar de forma que se tornem pesquisadores das respostas, entendendo que 0 saber não pode ser algo pronto e acabado.

Nesta proposta de educação o currículo passa a ser integrado, envolvendo a comunidade escolar em uma proposta transdisciplinar, o trabalho pedagógico deixa de ser fragmentado se entrelaçando entre as disciplinas, atividades de cultura, esporte e agregando saberes da comunidade onde a escola está inserida. O Conselho Municipal de Educação de Criciúma (Comec) em 15 de outubro de 2012 , fixou as normas para a Escola Integral do Ensino fundamental do Sistema Municipal de Ensino, todo o texto do Decreto é belíssimo, pois fala não só do acesso mas oferece qualidade, já no primeiro Artigo trata dessa temática "A educação Integral, entendida como formação plena do ser humano, amplia o conceito de educação [...] Tem por finalidade viabilizar a ampliação das oportunidades de aprendizagem, garantindo uma educação de qualidade" (CRICIÚMA, 2012, p 2).

A escola Padre Paulo Petruzzelis que funciona nas instalações do Bairro da Juventude é integral, mas não tem o currículo integrado, faz-se necessário lembrar que antes da implantação da escola a instituição já ofertava para as crianças e adolescentes que a frequentavam, atividades diversificadas. Com a implantação da escola, o ensino formal iniciou em um turno e as atividades que hoje foram ampliadas, no contraturno escolar. O Bairro da Juventude tem 67 anos e vem nesta caminhada sonhando com a educação de qualidade, que transforme a vida das crianças e adolescentes que o frequentam, mas é necessário levar em consideração que a maioria das crianças e adolescentes vem de uma realidade social muito difícil, pois na sua grande maioria vivem em situação de vulnerabilidade social. Desta forma o professor que ingressa na instituição traz consigo a formação acadêmica, mas logo percebe que é necessário ser um professor/educador, alguém que olhe nos olhos das crianças e tenha a sensibilidade de saber que aquele alguém que está diariamente em sala de aula traz consigo uma história de vida, que por vezes dificulta a aprendizagem, pois a sua maioria vive em vulnerabilidade social.

\section{FORMAÇÃO CONTINUADA}


A formação inicial nos cursos de graduação tem em suas Diretrizes Curriculares disciplinas teóricas e práticas, como os estágios e as práticas como componentes curriculares. Conforme Tardif (2014) os cursos de graduação formam "técnicos pedagógicos", pois a maioria dos professores recebem muita informação teórica, mas pouca vivência na escola, e começam a se questionar se realmente são professores, se tem conhecimento suficiente para ensinar. Tardif (2014) nos lembra que "o professor é antes de tudo, alguém que sabe alguma coisa e cuja função consiste em transmitir esse saber a outros", vale ressaltar que quando alguém decide fazer uma graduação traz consigo saberes adquiridos culturalmente, tanto ao longo da sua vida escolar como com o convívio em sociedade. "Resumidamente, digamos que o saber que o educador deve transmitir deixa de ser o centro de gravidade do ato pedagógico, é o educando, a criança, essencialmente, que se torna o modelo e o princípio da aprendizagem" (TARDIF, 2014, p 53). O ensino se desenvolve por meio das várias relações, onde o elemento humano é determinante e dominante, por isso, a importância da prática reflexiva, pois estes momentos podem ser momentos de formações continuadas.

Em 2016, no Bairro da Juventude foram promovidos encontros bimestrais entre todos os profissionais da educação, esses encontros foram chamados de formação continuada, pois diante de todos ao desafios do professor diariamente, entende-se que esses momentos são ricos em trocas, de saberes tanto teóricos como práticos. O professor ainda está muito ligado as obrigações com planejamento, provas, relatórios, necessitando ser estimulado para ser mais autônomo.

A instituição vem instigando os professores/educadores a ser tornarem mediadores do processo, ou seja, um profissional que domine o conteúdo da sua área de formação, mas que construa as atividades pedagógicas considerando os saberes, questionamentos das crianças e adolescentes, tendo uma escuta "sensível".

Para ser um mediador do processo é necessário ser um pesquisador, estudar mais e mais, pois o profissional não pode cair no erro de achar que a informação e o conhecimento são suficientes para ocorrer a aprendizagem significativa, pois o saber é sim, um passo além. Para Brandão (2012, p. 48) "o saber 
não é uma matéria do pensar que possa ser acumulada ou que possa ser passada em unidades de um plano para o outro". Na perspectiva de educação integral o profissional é mais exigido e envolvido com seu trabalho, pois torna-se alguém mais democrático, um profissional que está em constante formação.

Vale ressaltar que a formação para professores na perspectiva do trabalho com a educação integral não se trata de nenhuma novidade ou algum método revolucionário, mas vem desafiar os profissionais a repensarem nas práticas diárias, são momentos de aprendizagem que refletem nas relações com os tempos, espaços e pessoas.

\section{EDUCAÇÃO INTEGRAL}

Com a implantação de políticas públicas para viabilizar as escolas de tempo integral, a educação integral começa a ganhar mais significado, a escola abre suas portas para educadores muitas vezes sem formação acadêmica, com conhecimentos técnicos de áreas diversas, como capoeiristas, artesãos, músicos..., enfim fazendo ser necessário "reinventar" a relação de aprendizagem das crianças, adolescentes e comunidade escolar. Segundo Titton (2012, p.150) "Essas novas relações entre o ensinar e o aprender vêm demandando, também, outras mediações para a convivência e para a almejada transformação do currículo escolar”. As atividades propostas pela escola muitas vezes acabam sendo segregadas, as disciplinas são trabalhadas de forma conteudista, desafiando todos a superar estas barreiras e transformar tudo isso em uma educação voltada à integridade do ser humano. Segundo Titton (2012, p.154) "Mais do que nunca é preciso promover o encontro entre o mundo da escola com seus saberes, regras e procedimentos e a vida com sua diversidade de experiências e saberes". Quando se traz para a escola vivências significativas das realidade das crianças e adolescentes favorece a construção de um projeto pedagógico que faça sentido, pois as crianças e adolescentes são vistos como um ser completo, alguém que traz consigo sua história que tem a capacidade de aprender além dos conteúdos e desta forma se desenvolvendo nas suas múltiplas dimensões: física, intelectual, social, emocional e simbólica. Oportunizar educação 
integral significa democratizar e otimizar os espaços e tempos dentro ou fora da escola, melhorando a vida social, afetiva e emocional das crianças, adolescentes, pais, professores e todos os envolvidos no processo educacional.

Educar na perspectiva da educação integral extrapola a ampliação do tempo, bem como a ampliação de espaços; trata-se da necessidade de educar para ler, escrever, calcular, interpretar produzir textos e poesias, resolver problemas com as quatro operações e muito mais que isso, ou seja, a educação em sua integralidade visa ao ensino e à aprendizagem, ao olhar e ao cuidar do outro, visa à proteção e à emoção, respeito às diversidades; traduz a cultura de paz. O desejável é educar sujeitos que construam uma sociedade mais humanizada e menos violenta, a educação integral desenvolve-se e acontece em diferentes espaços, tempos e relações, é a educação da família, da escola, do campo de futebol, da rua, do bairro, etc. Pensar nessa grande rede é pensar na educação integral do nosso tempo (SANTOS, 2012, p. 338).

Ofertar oportunidades de educação integral torna-se tarefa da escola, principalmente na escola pública que muitas vezes fará o papel que muitas famílias não fazem, assegurando o atendimento e o desenvolvimento integral da criança e adolescente.

\section{ANÁLISE DE DADOS}

Em relação à apresentação e análise de dados, as/os professoras/es serão identificadas como professora 1, professora 2, professor 3, professora 4, professor 5, professor 6, professora 7 e professora 8. A professora 1 trabalha há 15 anos na instituição, a professora 2 há 05 anos, professor 3 ha 01 ano, professora 4 há 03 anos, professora 5 e 8 há 02 anos, professor 5 e 6 há 06 anos, professor 07 há 02 anos. Foi perguntado para os professores se conhecem as atividades que os alunos frequentam, todos responderam que sim. Quando questionados sobre como avaliam o desenvolvimento dos alunos nas atividades de contraturno, os professores responderam que avaliam como positivo, a professora 2 ressaltou:

"Enriquecedoras e complementares. As atividades desenvolvidas nas oficinas e Laboratórios agregam conhecimento e experiência a vida educacional das crianças e adolescentes. Uma vez que as mesmas tem a 
Criar Educação, Criciúma, v. 9, no 3, ago/dez. 2020 - PPGE - UNESC - ISSN 2317-2452

oportunidade de aprender e experimentar atividades e conteúdo para além do currículo formal".

Já o professor 3 respondeu:

"Positivo. Uma vez que entendo que existam duas modalidades de ensino e conhecimento. Percebemos que o conhecimento científico não está só atrelado ao currículo da escolar, mas abrange de maneira emancipatória e que se dissolve com atividades que julgamos como as que respeitam o mundo vivido dos alunos."

Percebe-se que as respostas apresentam conformidade com referencial teórico proposto, Santos (2012) onde a autora lembra que além de educar para aprender os conteúdos, educa-se para a construção de uma sociedade mais humanizada.

$\mathrm{Na}$ questão seguinte foi perguntado se as atividades dos Laboratórios, Oficinas Culturais e Esportivas contribuem para o desenvolvimento das múltiplas dimensões: física, intelectual, social, emocional e simbólica das crianças e adolescentes e o que o professor vê de positivo e o que poderia mudar. Todos responderam que as atividades contribuem para o desenvolvimento físico, intelectual, social, emocional e simbólica e todos os professores avaliam como positivo o trabalho realizado. $O$ professor 7 acredita que as atividades ofertadas pelos Laboratórios poderiam conter mais atividades de esporte. Já o professor 4 relatou:

\footnotetext{
"Vejo que a educação integral que está sendo trabalhado com os professores durante a formação continuada como algo que possa contribuir para o desenvolvimento do aluno em todas as suas dimensões, pois é através das oficinas e laboratórios que o aluno passa a ver a escola não somente como um monte de conteúdos e provas, mas que ali também podem aprender com prazer , através de experiencias , através de trocas de aprendizado."
}

Durante a escrita de nosso referencial trouxemos: (Tardif, 2014, p 53) "O ensino se desenvolve por meio das várias relações, onde o elemento humano é determinante e dominante, por isso, a importância da prática reflexiva, pois estes momentos podem ser momentos de formações continuadas". 
Também foi perguntado, o que entendem por educação integral. Todos responderam que é uma educação além do currículo formal, que considera a criança em todas as suas dimensões, a professora 5 escreveu:

"É aquela que prima pelo desenvolvimento integral do indivíduo, não trabalhando somente conteúdos curriculares, mas sim todas as áreas da vida, proporcionando um crescimento/desenvolvimento de todas as áreas: física, intelectual, social e emocional".

Em nosso referencial teórico citamos: "A educação Integral, entendida como formação plena do ser humano, amplia o conceito de educação [...] Tem por finalidade viabilizar a ampliação das oportunidades de aprendizagem, garantindo uma educação de qualidade" (Criciúma, 2012, p. 2), demostra que a professora considera que a educação integral vai além dos conteúdos escolares e está de acordo com a concepção de educação integral.

O último questionamento foi: Você considera ser possível construir Educação Integral, considerando o ensino Fundamental e o Bairro da Juventude? De que maneira isso se consolidaria? Todos responderam ser possível construir Educação Integral, a professora 8 respondeu:

"O Bairro da Juventude está caminhando já há algum tempo no conceito de Educação Integral. Existe ainda muito para se fazer, mas a instituição está muito à frente de tantos lugares que ainda somente pensam na Educação Integral como possibilidade. A formação dos profissionais (não só dos professores) que constituem o Bairro, direcionada a Educação Integral é uma forma bastante positiva para essa consolidação."

A professora 1 respondeu:

"Acredito fortemente na importância das atividades desenvolvidas por cada um dos setores. De forma muito particular, cada uma delas soma no desenvolvimento nas tantas dimensões de cada criança e adolescente. Essas atividades alcançam crianças que possivelmente não teriam tais oportunidades fora da Instituição. Existe um grande leque de questões positivas relacionadas a elas, mas obviamente ainda existe à se fazer, a se apropriar para sempre atender da melhor forma possível cada criança."

Segundo a resposta da professora, os momentos de formação preparados para os profissionais estão de acordo com o referencial teórico, pois em estudos 
realizados Tardif (2014) e Titton (2012), lembram que se faz necessário o encontro do mundo da escola com a vida com sua diversidade de experiências e saberes.

\section{CONCLUSÃO}

Este estudo foi de grande relevância para as autoras, pois proporcionou contato mais direto com os professores dos variados setores do Bairro da Juventude, também possibilitou momentos de reflexão sobre a formação continuada realizada em 2016 e mais estudos sobre a concepção de educação integral, onde faz-se necessário pensar, refletir, discutir e estudar o desenvolvimento humano.

$\mathrm{Na}$ pesquisa realizada todos os professores se mostraram comprometidos em tentar fazer educação integral, ou seja, entender que o currículo escolar é um espaço de disputa, onde os conteúdos são relevantes, mas as vivências trazidas pelas crianças e adolescentes também o são. Enquanto professor/educador, faz-se necessário ter consciência que em alguns momentos a aula planejada é substituída por momentos de reflexões, conversas sobre determinado assunto que não tem nada haver com um conteúdo escolar, mas sim com a vida, com a cidadania, com saber fazer escolhas e ampliar a visão de mundo.

Todos que participaram da pesquisa demonstraram clareza referente aos conceitos de tempo integral e educação integral, e podemos perceber que em muitas escolas onde 0 atendimento é realizado em tempo integral, os horários são divididos em turno e contraturno, ou seja, em um período as crianças estão em sala de aula no ensino formal e em outro período estão recebendo o reforço escolar e essa forma de educação não reflete a concepção de educação integral.

Vale ressaltar que na Instituição Bairro da Juventude as crianças estão em um período na escola e em outro ficam nos Laboratório Educativos até o terceiro ano e a partir do quarto ano, constroem junto aos professores educadores da Instituição uma agenda de atividades que serão realizadas durante o semestre. O objetivo é que todas as crianças e adolescentes desenvolvam autonomia, habilidades cognitivas, físicas, sociais e emocionais. 
Porém as respostas dos pesquisados demonstraram algumas fragilidades, pois em nenhum questionário apareceu que a educação integral é uma concepção de ensino que pode acontecer em todos os ambientes da escola, mas fora dela também, a qual envolve pais, comunidade, professores, funcionários, crianças, adolescentes, a cidade, cria redes de aprendizagens, respeita a diversidade, visa a proteção e a emoção. Quando o professor vive a educação integral as configurações de espaços começam a mudar, os tempos e as relações vão se construindo diferentes, pois começa-se a olhar para o outro, a ouvir o outro, respeitar as diferenças, o que causa estranheza em muitas pessoas.

Para quem foi aluno até a pouco tempo é difícil se "desconstruir", porque muitos professores vem de uma educação tradicionalista que considera o professor 0 detentor de todo saber, contudo a educação integral demonstra que é necessário dar voz para a criança e adolescente e que a aprendizagem acontece nas trocas e nas relações que se constituem a cada momento.

Também vale ressaltar que todos os questionários demostraram que os professores acreditam ser possível construir uma nova identidade pedagógica no Bairro da Juventude, envolvendo o ensino formal constituído pela escola EMEIEF. Pe. Paulo Petruzzellis, Laboratórios Educativos e atividades de esporte e cultura dentro da perspectiva da Educação Integral. Esta pesquisa demonstrou que os professores estão envolvidos na construção de uma educação mais humanizada, que os momentos de formações continuada realizadas durante $o$ ano de 2016 possibilitaram diálogos e reflexões sobre as práticas diárias. Percebe-se que os professores / educadores da Instituição Bairro da Juventude concordam ser possível construir uma identidade pedagógica dentro da perspectiva da educação integral, contribuindo com a transformação social das crianças, adolescentes, onde sejam protagonistas das suas vidas, saibam fazer escolhas, reflexões e pensem no bem coletivo.

\section{REFERÊNCIAS}

ACAFE. Metodologia da pesquisa. Unidade 3. Florianópolis, 2007. 
BAIRRO DA JUVENTUDE (Criciúma). Bairro da Juventude. Histórico. Disponível em: http://www.bairrodajuventude.org.br/?gclid=CPGc2ruRudICFQyAkQodQjIE5g Acesso em: 10 nov. 2016.

BRANDÃO, Carlos Rodrigues et al (Org.). O outro ao meu lado: Algumas ideias de tempos remotos e atuais para pensar a partilha do saber e a educação de hoje. In: MOLL, Jaqueline; ARROYO, Miguel; BRANDÃO, Carlos Rodrigues

(Org.). Caminhos da educação integral no Brasil: direito a outros tempos e espaços educativos. Porto Alegre: Penso, 2012. Cap. 2. p. 47-69.

BRASIL. Decreto no 7.083, de 27 de janeiro de 2010. Dispõe sobre o Programa Mais Educação. Disponível em: http://www.planalto.gov.br/ccivil_03/_ato20072010/2010/decreto/d7083.htm\#: :text=DECRETO\%20N\%C2\%BA\%207.083\%2C\%2 0DE\%2027,vista\%200\%20disposto\%20no\%20art. Acesso em: 30 jun. 2020

BRASIL. Ministério da Educação. Planejando a Próxima Década Conhecendo as 20 Metas do Plano Nacional de Educação. Brasília: Ministério da Educação, 2014. 63p. Disponível em:

http://pne.mec.gov.br/images/pdf/pne_conhecendo_20_metas.pdf. Acesso em: 02 dez. 2014.

CRICIÚMA. Lei 4307, de 02 de maio de 2002. Institui o sistema municipal de ensino de criciúma e dá outras providências. Disponível em:

https://www.criciuma.sc.gov.br/pmc/webroot/upload/ckfinder/files/LEl\%20COMEC\%2 $0 \% 204307-2002 \% 20-$

\%20Sistema\%20de\%20Ensino\%20\%20\%20\%20\%20\%20\%20\%20\%20\%20\%20\%2 0\%20V.pdf. Acesso em: 30 jun. 2020

CRICIÚMA. Decreto no 115, 12 de dezembro de 2004. Homologa Termo de Convênio celebrado entre o Município de Criciúma e o Bairro da Juventude dos Padres Rogacionistas. Disponível em: https://www.camaracriciuma.sc.gov.br/documento/decreto-no-115-2004-7753. Acesso em: 30 jun. 2020.

GIOLO, Jaime et al (Org.). Educação de tempo integral: Resgatando elementos históricos e conceituais para o debate. In: MOLL, Jaqueline; ARROYO, Miguel; BRANDÃO, Carlos Rodrigues (Org.). Caminhos da Educação Integral no Brasil: direito a outros tempos e espaços educativos. Porto Alegre: Penso, 2012. Cap. 5. p. 95-105.

OLIVEIRA, Maria Marly de. Como fazer pesquisa qualitativa.Petrópolis, RJ: Vozes, $2007.103 \mathrm{p}$. 
FREIRE, Paulo. Professora sim, tia não: cartas a quem ousa ensinar. São Paulo: Olho d'água, 1993. $127 \mathrm{p}$.

SANTOS, Claudia Pinto et al (Org.). Reflexão sobre o Programa Mais Educação na rede estadual de ensino da Bahia. In: MOLL, Jaqueline; ARROYO, Miguel; BRANDÃO, Carlos Rodrigues (Org.). Caminhos da educação integral no Brasil: direito a outros tempos e espaços educativos. Porto Alegre: Penso, 2012. Cap. 23. p. 336-344.

SIENA, Osmar. Metodologia da pesquisa cientifica: elementos para elaboração e apresentação de trabalhos acadêmicos. Disponível em:

http://www.mestradoadm.unir.br/site_antigo/doc/manualdetrabalhoacademicoatual. pdf. Acesso: 02 ago. 2016.

TARDIF, Maurice. Saberes docentes e Formação Profissional. São Paulo: Vozes, 2014. p. 31-55

TITTON, Maria Pauperio et al (Org.). Educação Integral : A construção de novas relações no cotidiano. In: MOLL, Jaqueline; ARROYO, Miguel; BRANDÃO, Carlos Rodrigues (Org.). Caminhos da educação integral no Brasil: direito a outros tempos e espaços educativos. Porto Alegre: Penso, 2012. Cap.9. p. 150-156. 